The INL is a

U.S. Department of Energy

National Laboratory

operated by

Battelle Energy Alliance

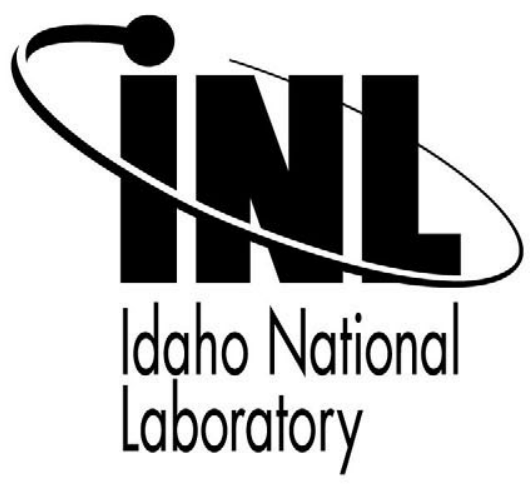

INL/CON-05-00078

PREPRINT

\section{Progress In High-} Temperature Electrolysis For Hydrogen Production Using Planar SOFC Technology

\section{AIChE 2005 Spring National Meeting}

\author{
J. Stephen Herring \\ James E. O'Brien \\ Carl M. Stoots \\ G. L. Hawkes \\ Joseph J. Hartvigsen \\ Mehrdad Shahnam
}

\section{April 2005}

This is a preprint of a paper intended for publication in a journal or proceedings. Since changes may not be made before publication, this preprint should not be cited or reproduced without permission of the author. This document was prepared as an account of work sponsored by an agency of the United States Government. Neither the United States Government nor any agency thereof, or any of their employees, makes any warranty, expressed or implied, or assumes any legal liability or responsibility for any third party's use, or the results of such use, of any information, apparatus, product or process disclosed in this report, or represents that its use by such third party would not infringe privately owned rights. The views expressed in this paper are not necessarily those of the United States Government or the sponsoring agency. 


\title{
PROGRESS IN HIGH-TEMPERATURE ELECTROLYSIS FOR HYDROGEN PRODUCTION USING PLANAR SOFC TECHNOLOGY
}

\author{
J. Stephen Herring, James E. O'Brien, Carl M. Stoots, G. L. Hawkes \\ Idaho National Laboratory \\ 2525 N. Fremont Ave., Idaho Falls, ID, 83415, USA \\ Joseph J. Hartvigsen \\ Ceramatec, Inc. \\ 2425 South 900 West, Salt Lake City, UT 84119, USA \\ Mehrdad Shahnam \\ FLUENT Inc. \\ 3647 Collins Ferry Road, Suite A, Morgantown, WV, 26505, USA
}

\section{ABSTRACT}

A research program is under way at the Idaho National Laboratory to assess the performance of solid-oxide cells operating in the steam electrolysis mode for hydrogen production over a temperature range of 800 to $900^{\circ} \mathrm{C}$. The research program includes both experimental and modeling activities. Selected results from both activities are presented in this paper. Experimental results were obtained from a ten-cell planar electrolysis stack, fabricated by Ceramatec ${ }^{1}$, Inc. The electrolysis cells are electrolyte-supported, with scandiastabilized zirconia electrolytes ( $140 \mu \mathrm{m}$ thick), nickel-cermet steam/hydrogen electrodes, and manganite air-side electrodes. The metallic interconnect plates are fabricated from ferritic stainless steel. The experiments were performed over a range of steam inlet mole fractions $(0.1-0.6)$, gas flow rates $(1000-4000 \mathrm{sccm})$, and current densities $\left(0\right.$ to $\left.0.38 \mathrm{~A} / \mathrm{cm}^{2}\right)$. Hydrogen production rates up to 90 Normal liters per hour were demonstrated. Stack performance is shown to be dependent on inlet steam flow rate. A three-dimensional computational fluid dynamics (CFD) model was also created to model high-temperature steam electrolysis in a planar solid oxide electrolysis cell (SOEC). The model represents a single cell as it would exist in the experimental electrolysis stack. Mass, momentum, energy, and species conservation and transport are provided via the core features of the commercial CFD code FLUENT ${ }^{1}$. A solid-oxide fuel cell (SOFC) model adds the electrochemical reactions and loss mechanisms and computation of the electric field throughout the cell. The FLUENT SOFC user-defined subroutine was modified for this work to allow for operation in the SOEC mode. Model results provide detailed profiles of temperature, Nernst potential, operating potential, anode-side gas composition, cathode-side gas composition, current density and hydrogen production over a range of stack operating conditions. Mean model results are shown to compare favorably with the experimental results obtained from the ten-cell stack tested at INL.

\section{INTRODUCTION}

Currently there is strong interest in the large-scale production of hydrogen as a secondary energy carrier for the non-electrical market. Hydrogen is of particular interest as a

\footnotetext{
${ }^{1}$ References herein to any specific commercial product, process, or service by trade name, trademark, manufacturer, or otherwise, does not necessarily constitute or imply its endorsement, recommendation, or favoring by the U.S. Government, any agency thereof, or any company affiliated with the Idaho National Engineering and Environmental Laboratory
} 
secondary energy carrier because it has the potential to be storable, transportable, and environmentally benign. Hydrogen is now produced primarily via steam reforming of methane. From a long-term perspective, methane reforming is not a viable process for large-scale production of hydrogen as a major energy carrier since such fossil fuel conversion processes consume non-renewable resources and emit greenhouse gases to the environment. Consequently, there is a high level of interest in production of hydrogen from water splitting via either thermochemical or electrolytic processes (e.g., National Research Council, 2004).

High-temperature nuclear reactors have the potential for substantially increasing the efficiency of hydrogen production from water splitting, with no consumption of fossil fuels, no production of greenhouse gases, and no other forms of air pollution. Thermal water-splitting for hydrogen production can be accomplished via high-temperature electrolysis or thermochemical processes, using high-temperature nuclear process heat. In order to achieve competitive efficiencies, both processes require high-temperature operation $\left(\sim 850^{\circ} \mathrm{C}\right)$. Thus these hydrogen-production technologies are tied to the development of advanced hightemperature nuclear reactors. High-temperature electrolytic water splitting supported by nuclear process heat and electricity has the potential to produce hydrogen with overall system efficiencies near those of the thermochemical processes (Yildiz, 2003; IAEA, 1999), but without the corrosive conditions of thermochemical processes and without the fossil fuel consumption and greenhouse gas emissions associated with hydrocarbon processes. Specifically, a high-temperature advanced nuclear reactor coupled with a high-efficiency hightemperature electrolyzer could achieve a competitive thermal-to-hydrogen conversion efficiency of 45 to $55 \%$.

A research program is under way at the Idaho National Laboratory (INL) to simultaneously address the technical and scale-up issues associated with the implementation of solid-oxide electrolysis cell technology for hydrogen production from steam. The research program includes an experimental program aimed at performance characterization of electrolysis cells and stacks. Results of single-cell tests have been documented in several recent papers (O'Brien et al., Herring et al., 2004). Single (button) cell tests are useful for basic performance characterization of electrode and electrolyte materials and of different cell designs (e.g., electrode-supported, porous metal substrate-supported). The single-cell results demonstrated efficient small-scale hydrogen production, with performance close to theoretical predictions. Cell performance was shown to be continuous from the fuel-cell to the electrolysis mode. The effects of steam starvation and thermal cycling on cell performance parameters were demonstrated. Based on these preliminary results, high-temperature electrolysis appears to be a viable means for hydrogen production using nuclear energy.

The INL research program includes experimental, modeling and materialsdevelopment tasks. The experimental results presented in this paper were obtained from a ten-cell planar electrolysis stack fabricated by Ceramatec, Inc.. Experimental results include voltage-current behavior, stack area-specific resistance, hydrogen production rates, electrolysis efficiency, and internal stack temperature measurements over a range of operating conditions. For detailed SOEC modeling, the commercial CFD code FLUENT was selected. Fluent Inc. was funded by the US Department of Energy National Energy Technology Laboratory (DOE-NETL) to develop a solid-oxide fuel cell (SOFC) module for coupling to the core mass, momentum, energy, and species conservation and transport features of the FLUENT CFD code (Prinkey et al., 2004). The SOFC module adds the electrochemical 


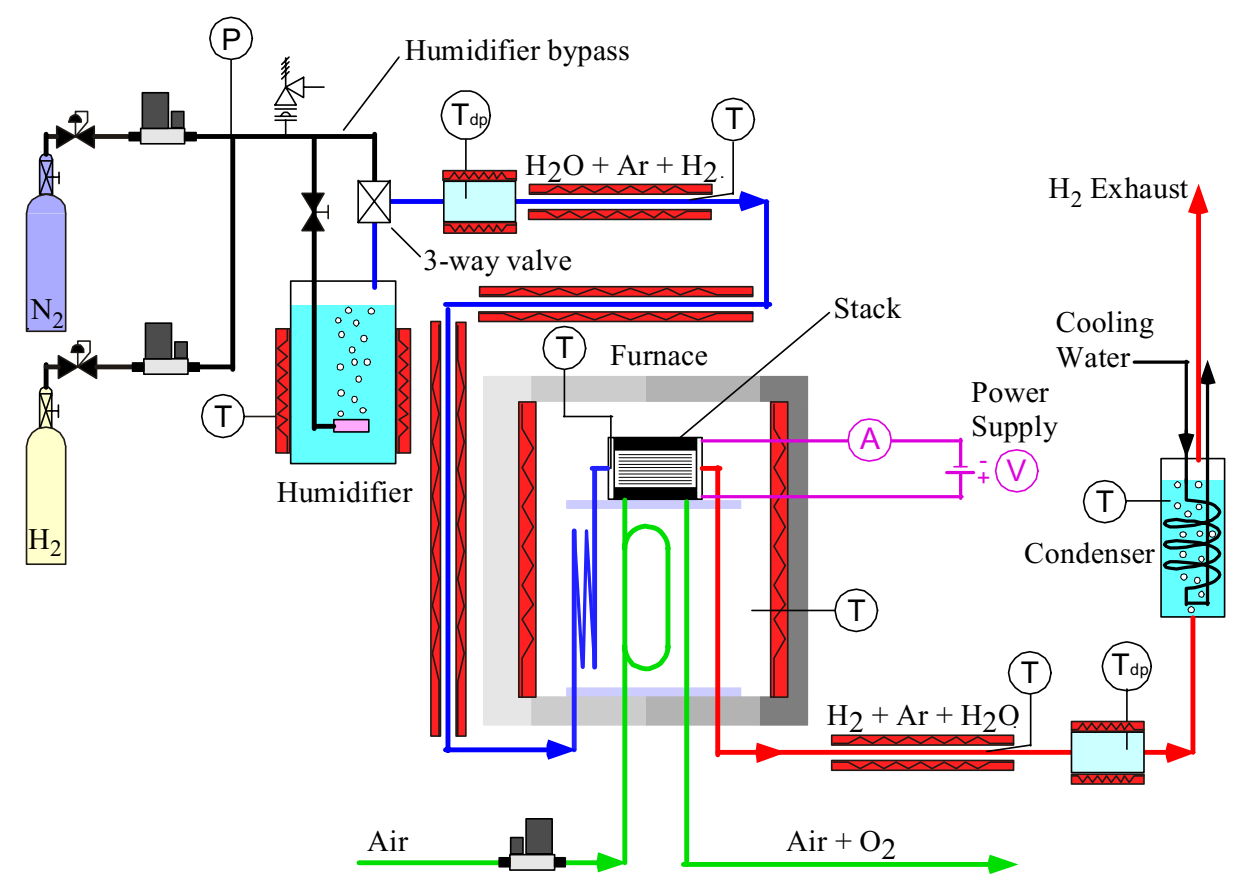

Figure 1: Schematic of experimental apparatus for electrolysis stack testing.

reactions and loss mechanisms and computation of the electric field throughout the cell. The FLUENT SOFC user-defined subroutine was modified for this work to allow for operation in the SOEC mode. Model results provide detailed profiles of temperature, Nernst potential, operating potential, anode-side gas composition, cathode-side gas composition, current density and hydrogen production over a range of stack operating conditions. Results of the numerical model are compared to experimental results obtained from a ten-cell stack tested at INL.

\section{APPARATUS}

A schematic of the stack-testing apparatus is presented in Fig. 1. Primary system components include gas supply cylinders, gas mass-flow controllers, a humidifier, dewpoint measurement stations, temperature and pressure measurement, high temperature furnace, and a solid oxide electrolysis stack. Nitrogen was used as an inert carrier gas. The use of a carrier gas allows us to independently vary both the partial pressures and the flow rates of the steam and hydrogen gases while continuing to operate at atmospheric pressure. The flow rates of nitrogen, hydrogen and air are established by means of precision mass-flow controllers (Hastings Model HFC-302, with Hastings Model 400 electronics). Air flow to the stack is supplied by the laboratory shop air system, after passing through a two-stage extractor / dryer unit.

Downstream of the mass-flow controller, nitrogen is mixed with a smaller flow of hydrogen gas. Hydrogen is included in the inlet flow as a reducing gas in order to prevent oxidation of the nickel cermet electrode material. The nitrogen / hydrogen gas mixture is mixed with steam by means of a heated humidifier. The humidifier consists of a heated stainlesssteel vessel containing demineralized / deionized water through which the nitrogen / hydrogen flow is bubbled. The dewpoint temperature of the steam / hydrogen / nitrogen gas mixture 
exiting the humidifier is monitored continuously using a precision dewpoint sensor (Vaisala Model HMP247). The humidifier is fitted with a clamp heater and is externally insulated. The humidifier temperature is maintained at a constant setpoint value using feedback control. Since the vapor pressure of the water and the resulting partial pressure of the steam exiting the humidifier are determined by the water bath temperature, the water vapor mass flow rate is directly proportional to the carrier gas flow rate for a specified bath temperature. Also, since the nitrogen and hydrogen flow rates are fixed by the mass flow controllers, and the steam partial pressure is fixed by the bath temperature, the

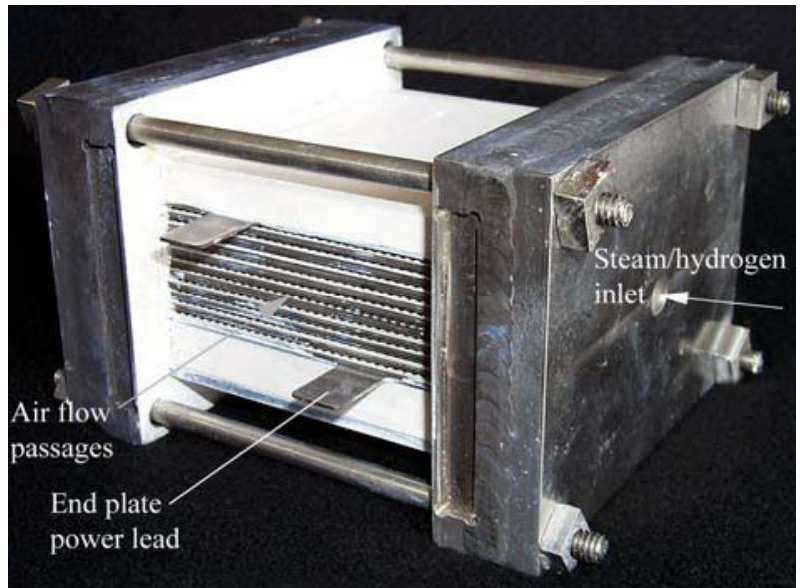

Figure 2. Detail of stack. complete gas composition is precisely known at all times. All gas lines located downstream of the humidifier are heat-traced in order to prevent steam condensation. Gas line temperatures are monitored by thermocouples and controlled by means of variable transformers.

A close-up photograph of the test article, a 10-cell solid-oxide electrolysis stack, is shown in Fig. 2. The stack was fabricated by Ceramatec, Inc. of Salt Lake City, UT. The percell active area is $64 \mathrm{~cm}^{2}$. It is designed to operate in cross flow, with the steam / hydrogen gas mixture entering the inlet manifold on the right in the photograph, and exiting through the outlet manifold, visible on the left in the photograph. Air flow enters at the rear though an air inlet manifold (not visible in Fig. 3) and exits at the front directly into the furnace. The power lead attachment tabs, integral with the upper and lower interconnect separator plates are also visible in the photograph. Stack operating voltages were measured using wires that were directly spot-welded onto these tabs. Since the stack air outlet plane is not enclosed, the small air flow channels are accessible for instrumentation. Four intermediate cell voltages were monitored using small-diameter wires inserted into these air flow channels. In addition, four miniature thermocouples (inconel-sheathed, 0.010-inch $(250 \mu \mathrm{m}) \mathrm{OD}$, mineral-insulated, ungrounded, type-K) were inserted into the air flow channels to monitor internal stack temperatures.

The internal components of the stack are shown in Fig. 3. The interconnect plate, shown on the left in Fig. 3, is fabricated primarily from low-chromium ferritic stainless steel. It includes an impermeable separator plate $(\sim 0.46 \mathrm{~mm}$ thick) with edge rails and two corrugated / perforated "flow fields," one on the air side and one on the steam/hydrogen side. The height of the flow channel formed by the edge rails and flow fields is $1.0 \mathrm{~mm}$. Each flow field includes 32 perforated flow channels across its width to provide uniform gas-flow distribution. The steam / hydrogen flow field (shown in Fig. 3) is fabricated from nickel foil. The air-side flow field is ferritic stainless steel. The interconnect plates and flow fields also serve as electrical conductors and current distributors. To improve performance, the air-side separator plates and flow fields are pre-surface-treated to form a rare-earth conductive oxide scale. A perovskite rare-earth coating is also applied to the separator-plate oxide scale by either screen printing or plasma spraying. On the steam/hydrogen side of the separator plate, a thin $(\sim 10$ $\mu \mathrm{m})$ nickel metal coating is applied. 




Figure 3. Interconnect plate and single electrolysis cell.

The electrolyte / electrode assembly is shown on the right of Fig. 3. The electrolyte is scandia-stabilized zirconia, about $140 \mu \mathrm{m}$ thick. The air-side electrode (anode in the electrolysis mode), visible in the figure, is a strontium-doped manganite. The electrode is graded, with an inner layer of manganite/ zirconia $(\sim 13 \mu \mathrm{m})$ immediately adjacent to the electrolyte, a middle layer of pure manganite $(\sim 18 \mu \mathrm{m})$, and an outer cobaltite bond layer. The steam/ hydrogen electrode (cathode in the electrolysis mode) is also graded, with a nickelzirconia cermet layer $(\sim 13 \mu \mathrm{m})$ immediately adjacent to the electrolyte and a pure nickel outer layer $(\sim 10 \mu \mathrm{m})$.

Measurement of the outlet dewpoint temperature, downstream of the electrolysis stack, allows for direct determination of the change in dewpoint, the rate of steam reduction and the corresponding rate of hydrogen production during electrolysis testing. All testing was performed at essentially ambient laboratory pressure, about $85 \mathrm{kPa}$ for our $4700 \mathrm{ft}$. elevation.

Stack voltage and current values were controlled by means of a programmable DC power supply (Lambda Zup 20-40), rated for $20 \mathrm{~V}$ and 40 amps. The power supply could be operated in either the constant-current or constant voltage modes. This power supply was interfaced to the system controller computer via an RS232 interface. Cell amperage and the voltage across the stack are monitored continuously. Stack current measurements are obtained from the power supply, with redundant measurements provided by a precision shunt $(50 \mathrm{~A}=200 \mathrm{mV})$.

Signals from all thermocouple channels, mass-flow controllers, pressure transducer, and stack voltage taps were wired into a modular data acquisition system (National Instruments Model SCXI) which was configured for this application with a 32-channel analog input module and an eight-channel analog output module. The analog output module was used to provide control signals $(4-20 \mathrm{~mA})$ for feedback temperature control of the humidifier, the humidity measurement stations, and the furnace. Data acquisition and instrument control were implemented for these tests using a Labview (National Instruments, version 6.1) program (virtual instrument) specifically created for this experiment. Temperature control of the humidifier, the humidity sensing volumes, and the furnace was accomplished using customized PID control algorithms. 


\section{DATA REDUCTION}

Open-cell potentials can be predicted for any gas composition from the Nernst equation, which for the hydrogen / oxygen / steam system takes the form:

$$
E=\frac{-\Delta \bar{g}_{f}^{o}}{2 F}-\frac{R_{u} T}{2 F} \ln \left[\left(\frac{y_{H 2 O}}{y_{H 2} y_{O 2}^{1 / 2}}\right)\left(\frac{P}{P_{s t d}}\right)^{-1 / 2}\right]
$$

Since we are using air as our source of oxygen, the value of $y_{02}$ at the stack inlet is fixed at 0.21 . In the stack configuration, potentials are usually measured across the entire stack, so the overall stack open-cell potential is given by:

$$
E_{\text {stack }}=N_{\text {cells }} E
$$

where $E$ is the single-cell open-cell potential, from Eqn. (1).

Inlet and outlet gas stream dewpoint temperatures were directly measured in this work. Aside from the fact that the measured difference between outlet and inlet dewpoint temperature (dewpoint depression) is a useful indication of cell performance, measured dewpoints permit direct determination of inlet and outlet steam mole fractions and the corresponding hydrogen production rate. From the measured dewpoint temperatures, water vapor pressures may be calculated from an appropriate correlation (e.g., Antoine). The inlet and outlet mole fractions of steam can then be obtained from:

$$
y_{H 2 O, i}=\frac{P_{H 2 O, i}}{P} ; \quad y_{H 2 O, o}=\frac{P_{H 2 O, o}}{P} .
$$

It should be noted that since the mole fraction of steam in the inlet gas flow is determined strictly by the dewpoint temperature, the total inlet flow rate of steam is therefore directly proportional to the sum of the molar flow rates of nitrogen plus hydrogen:

$$
\dot{N}_{H 2 O, i}=\frac{\left(\dot{N}_{N 2}+\dot{N}_{H 2, i}\right) y_{H 2 O, i}}{1-y_{H 2 O, i}} .
$$

The magnitude of the total inlet steam flow rate is important in determining whether or not steam starvation is likely to occur during electrolysis operation.

The inlet mole fraction of hydrogen, $y_{H 2, i}$ is determined by the steam mole fraction and the ratio of the nitrogen flow rate to the hydrogen flow rate, both of which are determined by the setpoint values established on the mass flow controllers:

$$
\begin{gathered}
y_{H 2, i}=\frac{1-y_{H 2 O, i}}{1+\dot{N}_{N 2} / \dot{N}_{H 2, i}} \\
\dot{N}_{N 2}=Q_{s, N 2} \frac{P_{s t d}}{R_{u} T_{s t d}}
\end{gathered}
$$




$$
\dot{N}_{H 2, i}=Q_{s, H 2} \frac{P_{s t d}}{R_{u} T_{s t d}} .
$$

Finally, the molar rates of hydrogen production and steam consumption may be determined from:

$$
\begin{gathered}
\Delta \dot{N}_{H 2}=-\Delta \dot{N}_{H 2 O} \\
\Delta \dot{N}_{H 2}=\dot{N}_{H 2 O, i}-\left(\dot{N}_{H 2 O, i}+\dot{N}_{H 2, i}+\dot{N}_{N 2}\right) y_{H 2 O, o} .
\end{gathered}
$$

The molar rates of hydrogen production and steam consumption during electrolysis can also be predicted independently from the measured stack electrical current:

$$
\Delta \dot{N}_{H 2}=\frac{I}{2 F} N_{\text {cells }}=-\Delta \dot{N}_{H 2 O}
$$

where $N_{\text {cells }}$ is the number of cells in the stack. The product of the electrical current and the number of cells is the total ionic current in the stack.

Since we have directly measured both inlet and outlet dewpoint temperatures, we have generated plots comparing hydrogen production rates based on stack current to hydrogen production rates based on the measured change in dewpoint over a range of stack current densities.

An important performance parameter that quantifies the ohmic losses associated with the operation of solid-oxide electrolysis cells is the area-specific resistance (ASR). This quantity is defined as:

$$
A S R=\frac{E-E_{O C V}}{i} ; \quad i=\frac{I}{A_{\text {cell }}}
$$

where $E$ is the applied potential, $E_{O C V}$ is the Nernst or open-cell potential and $i$ is the current density $\left(\mathrm{A} / \mathrm{cm}^{2}\right)$.

In the electrolysis mode of operation, the electrochemical reaction is endothermic, and ohmic heating is always present. At operating voltages between the open-cell potential and the thermal neutral voltage, the endothermic reaction heat requirement is greater in magnitude than the ohmic heating, and a net cooling effect prevails in the stack (O'Brien et al., 2004). The thermal neutral voltage, given by:

$$
V_{t n}=\frac{\Delta h_{R}}{2 F}
$$

is $1.287 \mathrm{~V}$ at $800^{\circ} \mathrm{C}$, or $12.87 \mathrm{~V}$ for the 10 -cell stack. Beyond this operating voltage, ohmic heating exceeds the endothermic reaction heat requirement and a net heating effect prevails.

\section{NUMERICAL MODEL}

The numerical model developed for this paper was based on the geometry of a single SOEC cell taken from the stack described previously. The numerical domain extends from the center plane of one separator plate to the center plane of the next separator plate. Symmetry boundaries are applied at the top and bottom of the model. Representations of the numerical 
model are presented in Figure 4. In the top left portion of Figure 4, the full model is shown to scale. Since the model includes only one cell, the model geometry is quite thin in the vertical (z) direction. To show more detail, the model is shown in the bottom left portion of Figure 4 with a vertical exaggeration of $10 x$ in the $z$-direction. An exploded view with the $10 x$ vertical exaggeration is shown in the right half of the figure.

In the exploded view, the bottom element is the bottom separator plate. Since we are trying to represent a unit cell extracted from a larger stack, the bottom and top separator plates in the numerical model are only half as thick (i.e., $0.19 \mathrm{~mm}$ ) as the hardware separator plates. Therefore, the top and bottom boundaries of the numerical model represent symmetry planes and the boundary conditions on those faces are set accordingly. The edge rails are shown attached to the bottom separator plate. In the stack hardware, the edge rails are fabricated from the same material as the separator plates, but they are separate pieces.

The next element in the numerical model is the steam/hydrogen flow channel. The flow channels are the regions in the stack between the separator plate, the edge rails and the electrodes in which the corrugated/perforated "flow fields" are located. The steam/hydrogen flow channel has been specified as a high-porosity porous-media region with metallic nickel as the solid material and with anisotropic permeability, much higher in the primary flow direction than in the cross flow directions. The height of the flow channel is the set by the thickness of the edge rails, $1.019 \mathrm{~mm}$.

The next three layers in the numerical model are associated with the electrolyte/electrode assembly, as shown in the right half of Figure 4. The FLUENT SOFC module treats the electrolyte as a 2-D planar element. Therefore the electrolyte in the model has geometrical thickness of zero. On either side of the electrolyte are the electrodes which are created with 3-D elements. Therefore, the electrolyte/electrode assembly in the model is only as thick as the two electrodes. Around the outer periphery of the electrolyte/electrode assembly, we have include an "insulator" with the properties of YSZ. The insulator prevents an electrical short circuit between the top and bottom edge rails. No ionic transport occurs through this insulator.

The next element in the numerical model is the air/oxygen flow channel. It has also been specified as a high-porosity porous media region with ferritic stainless steel as the solid material and with the same anisotropic permeabilities and flow channel height used in the steam/hydrogen flow channel. The top separator plate and edge rails are identical to those on the bottom, but the edge rails are oriented perpendicular to the bottom edge rails to allow for the cross flow arrangement. The bottom separator plate in the FLUENT model serves as the electrical ground and the top separator plate serves as the current source.

Additional parameters specified in the numerical model include the electrode exchange current densities and several gap electrical contact resistances. These quantities were determined empirically by comparing FLUENT predictions with stack performance data. The FLUENT model uses the electrode exchange current densities to quantify the magnitude of the activation overpotentials via a Butler-Volmer equation (Prinkey et al., 2004). A radiation heat transfer boundary condition was applied around the periphery of the model to simulate the thermal conditions of our experimental stack, situated in a high-temperature electrically heated radiant furnace. The edges of the numerical model are treated as a small surface in a large 

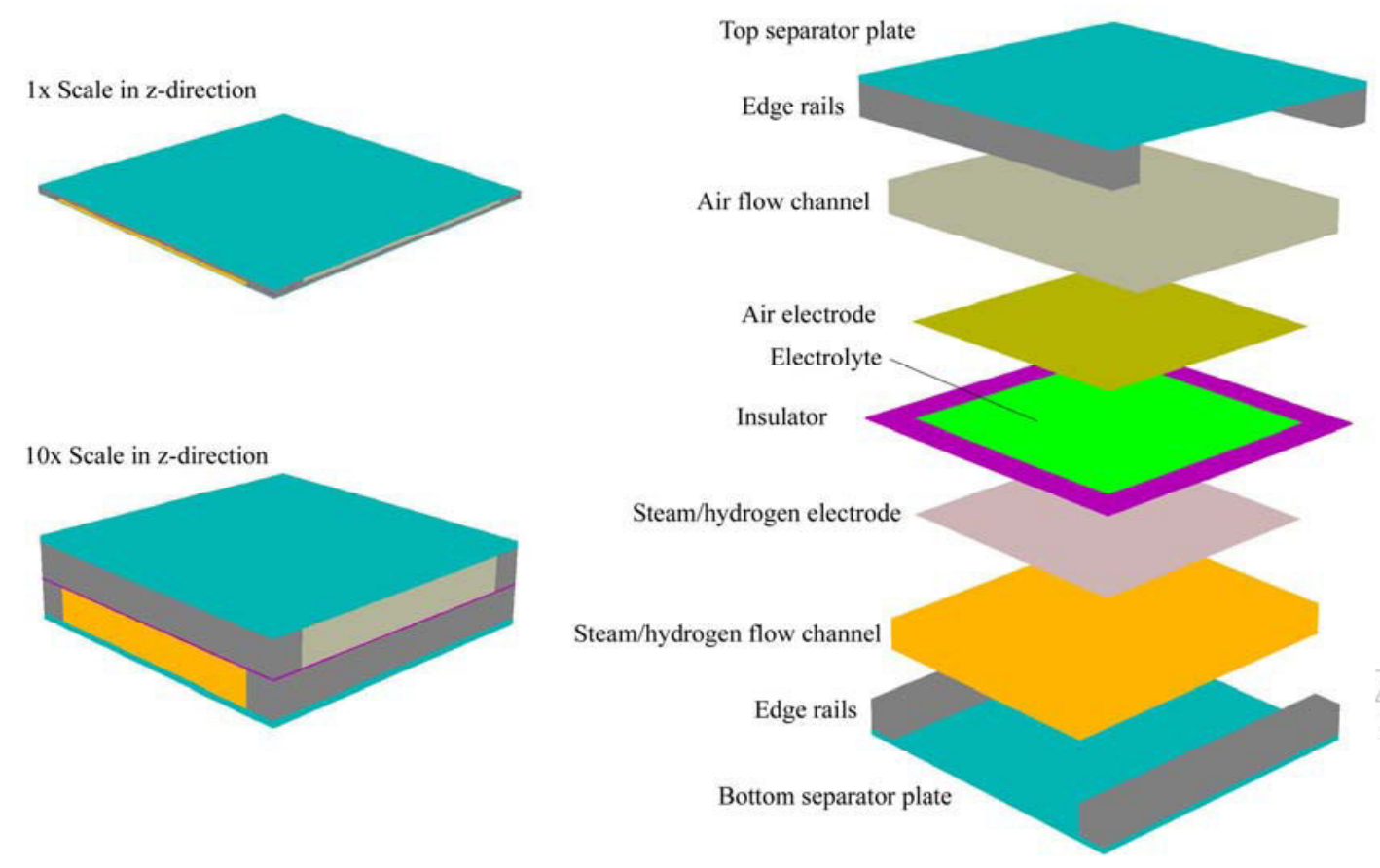

Figure 4. Fluent single-cell SOEC model.

enclosure with an effective emissivity of 1.0 , subjected to a radiant temperature of $1103 \mathrm{~K}$, equal to the gas-inlet temperatures.

The gas flow inlets are specified in the FLUENT model as mass-flow inlets, with the gas inlet temperatures are set at $1103 \mathrm{~K}$ and the inlet gas composition determined by specification of the mass fraction of each component. The gas flow rates used in the model were the same as those used for the experimental base case, on a per-cell basis. For example, the base case for the steam/hydrogen inlet used a total inlet mass flow rate of 8.053 $x 10^{-6} \mathrm{~kg} / \mathrm{s}$, with nitrogen, hydrogen and steam mass fractions of $0.51,0.0074$, and 0.483 , respectively. The base case air flow rate was $4.33 \times 10^{-6} \mathrm{~kg} / \mathrm{s}$.

Details of the core mass, momentum, energy, and species conservation and transport features of FLUENT are documented in detail in the FLUENT user manual (FLUENT, 2004). Details of the electrochemical reactions, loss mechanisms, electric field computation, and electrode porous media constitutive relations are documented by Prinkey et al. (2004). This reference also documents the treatment of species and energy sources and sinks arising from the electrochemistry at the electrode-electrolyte interfaces.

\section{RESULTS}

A series of DC potential sweeps was acquired in order to characterize the performance of the stack over a range of operating conditions. Each sweep was performed in the electrolysis mode with the furnace temperature and gas flow rates set at fixed values, but with the power supply programmed to vary the applied stack voltage over a range, typically from 8 to 14 volts. The power supply sweep rate was set at $\sim 8 \mathrm{mV} / \mathrm{s}$, so the duration of each sweep was about 25 minutes. At the gas flow rates used in the stack, the response time of the downstream dewpoint sensor was fast enough to provide continuous outlet dewpoint measurements during 


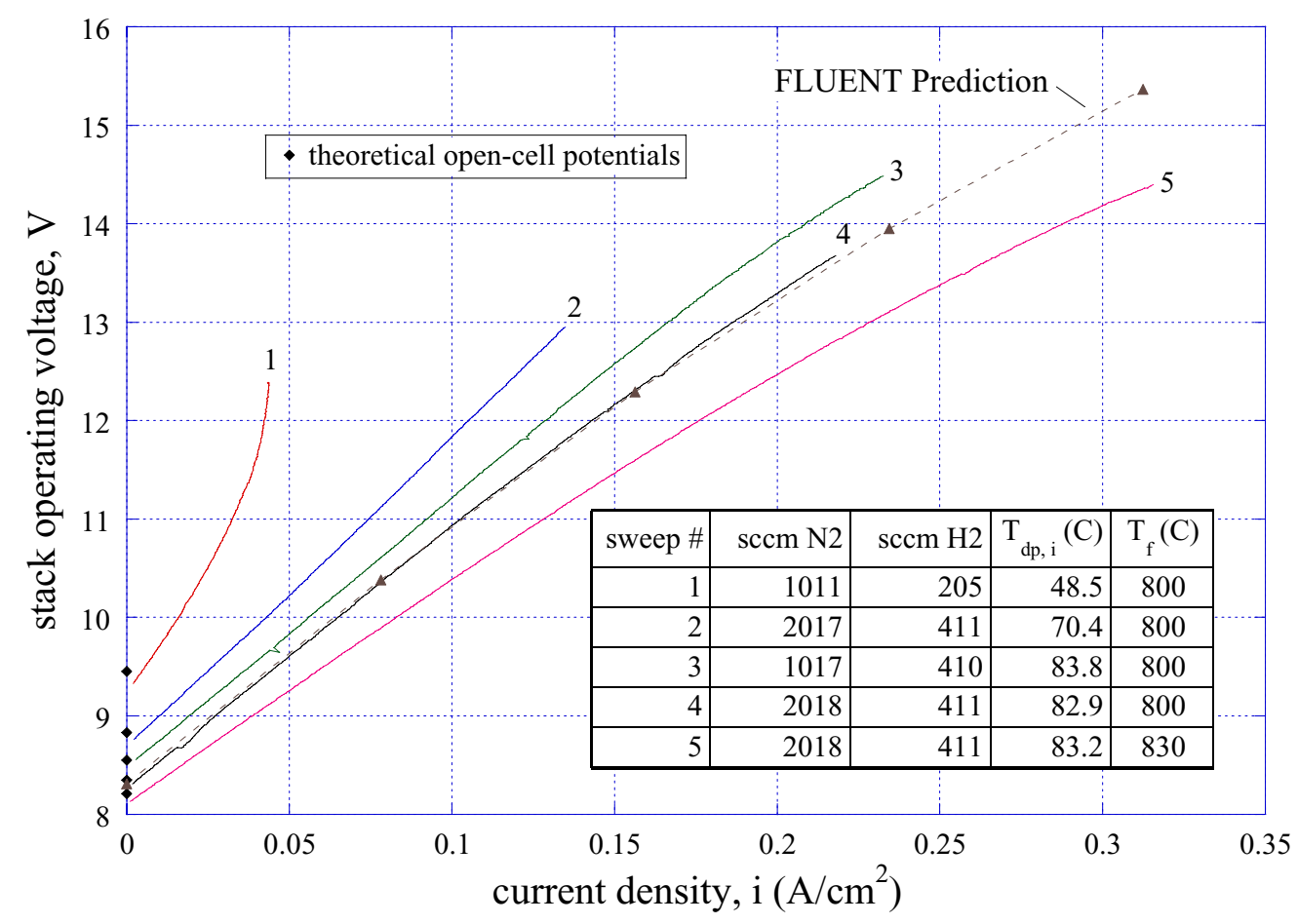

Figure 5. Stack operating potential as a function of current density.

the sweep. These sweeps were useful for obtaining information about cell area-specific resistance (ASR) values and steam starvation limits.

Results of several representative sweeps are shown in Fig. 5 in the form of operating voltage versus current density. Test conditions for each of the five experimental sweeps shown are tabulated in the figure. Four of the sweeps were obtained at a furnace temperature of $800^{\circ} \mathrm{C}$ and one at $830^{\circ} \mathrm{C}$. Inlet dewpoint values were varied as shown. Theoretical opencell potential values are also shown in the figure for each sweep using a single data point at zero current density. Note that the measured open-cell potentials are in excellent agreement with these theoretical values for each sweep. In additional to the experimental curves, a FLUENT prediction is also shown. This prediction was obtained for the conditions of sweep 4, with the gap contact resistance values empirically adjusted to yield an overall area-specific resistance value that matches the experimentally observed value. Additional FLUENT predictions of local temperatures and current densities presented later were obtained using the same procedure.

Sweep \#1 was performed with a relatively low inlet steam flow rate, corresponding to the low inlet dewpoint value of $48.5^{\circ} \mathrm{C}$ and relatively low nitrogen and hydrogen flow rates. This sweep has a relatively high slope on i-V coordinates, indicating a high ASR value. This sweep also clearly shows the effects of steam starvation; the slope of the i-V curve increases dramatically as the current density is increased. The outlet dewpoint temperature corresponding to the highest current density shown in this figure was only $4^{\circ} \mathrm{C}$. Sweep $\# 2$ was performed at an intermediate steam concentration, with an inlet dewpoint temperature of $70^{\circ} \mathrm{C}$. This sweep exhibits nearly linear behavior over the range of current densities shown, with a much smaller slope than sweep \#1. Sweeps 3 and 4 are nearly linear at low current densities, then slightly concave-down at higher current densities. Sweep \#5 has a shallower slope than 


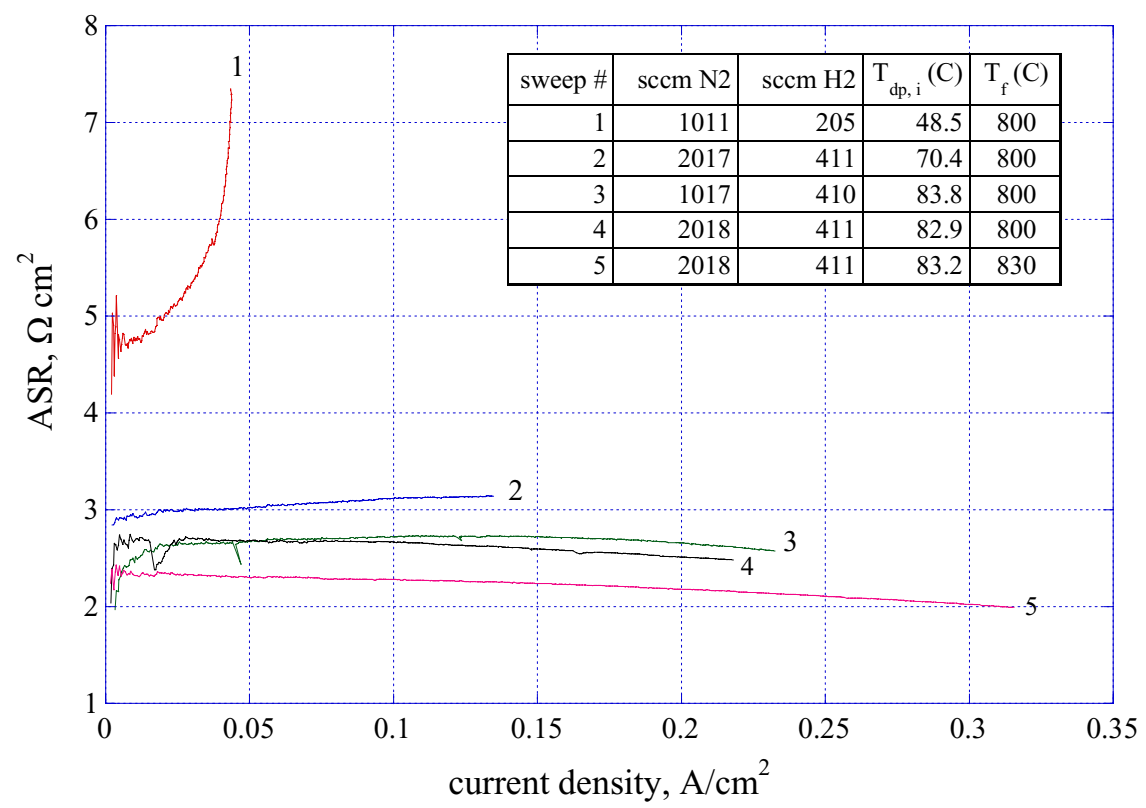

Figure 6. Per-cell area-specific resistance measured during DC potential

the others, consistent with the higher operating temperature of $830^{\circ} \mathrm{C}$. This $\mathrm{i}-\mathrm{V}$ curve also shows more distinct concave-down characteristics at higher current densities.

Per-cell area-specific resistance values corresponding to the sweeps of Fig. 5 are presented in Fig. 6 as a function of current density. Highest ASR values were observed for the cases with low steam concentrations. Sweep \#1 had ASR values near 4.5 at low current density, increasing rapidly for higher current densities, due to steam starvation. Sweep \#2, at intermediate steam concentration had an intermediate ASR value near 3.0, increasing slightly with increasing current density. Sweeps 3 and 4 were similar, with ASR values near 2.5, decreasing slightly at high current density. Sweep \#5, at an operating temperature of $830^{\circ} \mathrm{C}$ showed the lowest ASR value, around 2.2, decreasing significantly with increasing current density.

Hydrogen production rates can be calculated directly from the stack electric current (Eqn. 10) and independently from the measured inlet and outlet dewpoint measurements (Eqn. 9). A representative plot of hydrogen production during DC potential sweep \#2 is shown in Fig. 7. The left-hand vertical scale is in sccm and the right-hand vertical axis is in NL/hr. The current-based hydrogen production rate is simply a straight line since hydrogen production is directly proportional to the current. The dewpoint-based measurement shows some scatter associated with the instantaneous measured inlet and outlet dewpoint values. Agreement between the two measurements is generally very good. Hydrogen production rates as high as $90 \mathrm{NL} / \mathrm{hr}$ were achieved with this stack.

Temperatures measured during DC potential sweep \#4 are presented in Fig. 8 as a function of operating voltage. Stack internal temperature measurements were obtained using miniature thermocouples inserted into the air flow channels. Stack internal \#1 was located in the center position of the center air flow channel, stack internal \#2 was located along the edge of the center cell closest to the steam/hydrogen exit, stack internal \#3 was located along the edge of the center cell closest to the steam/hydrogen inlet, and stack internal \#4 was located 


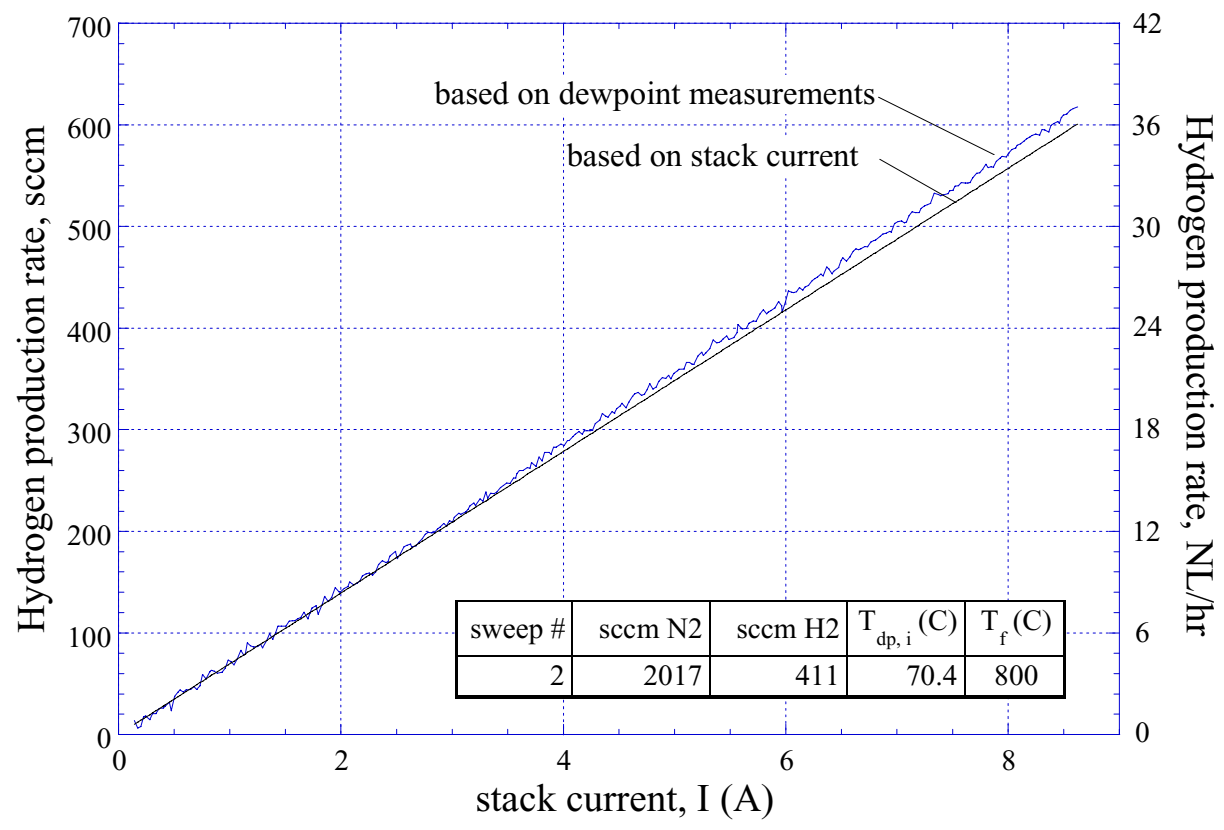

Figure 7. Hydrogen production rates during DC potential sweep.

at the center of the top air flow channel. The air inlet temperature is obtained from a thermocouple located inside the air inlet manifold. This thermocouple is used as the process variable for feedback control of the furnace power. The "furnace" temperature is obtained form a thermocouple located in the main part of the furnace outside of the test fixture.

The air inlet temperature remains virtually fixed during the DC potential sweep because this temperature is used for feedback control to maintain a constant stack operating temperature. The four internal stack thermocouples respond as expected during the sweep.

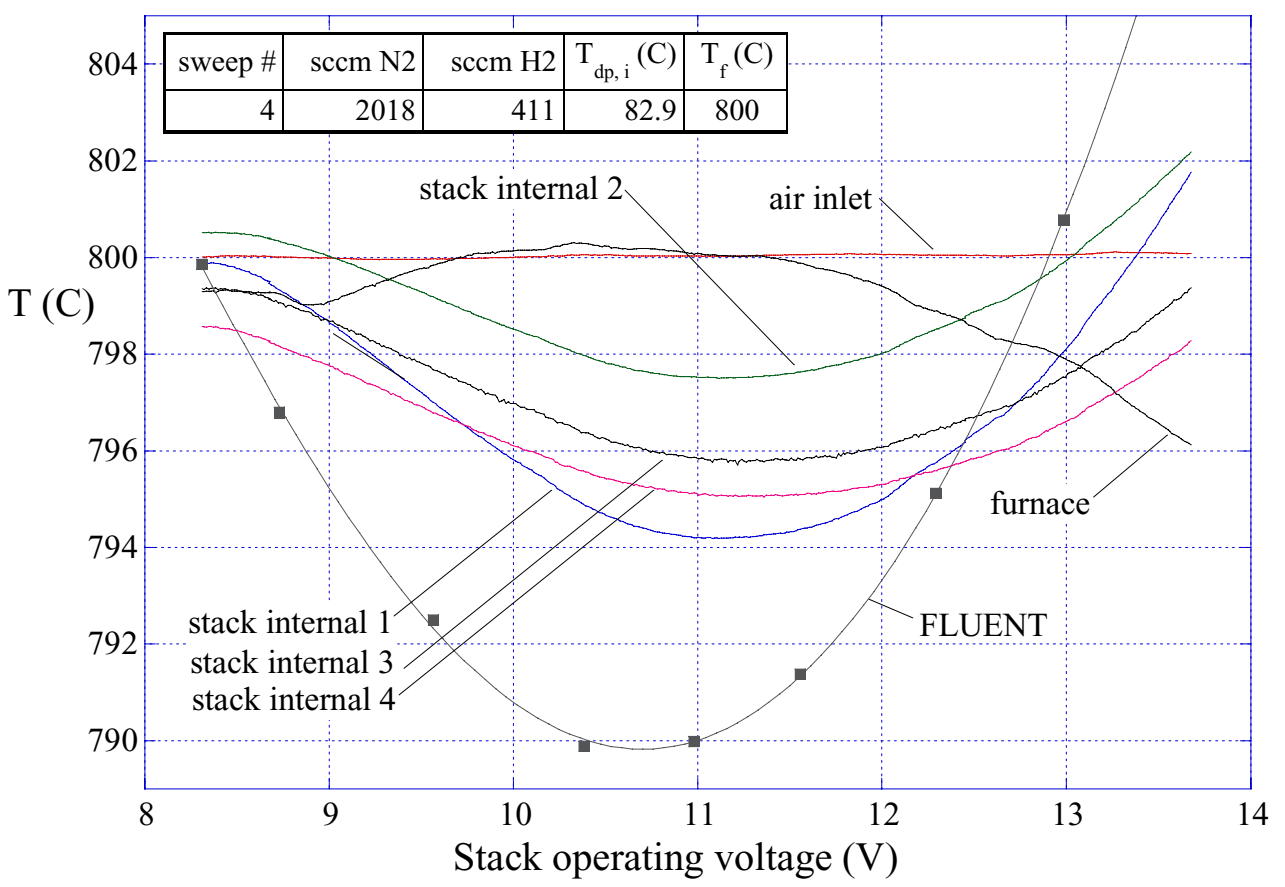

Figure 8. Stack temperatures during DC potential sweep. 
At voltages between the open-cell potential and the thermal neutral voltage, in the electrolysis mode, the stack internal temperatures are lower than the gas inlet and furnace setpoint temperatures because at this operating condition, the endothermic reaction heat requirement is greater than the ohmic heating (O'Brien et al., 2004) and there is a net cooling effect on the stack. A thermal minimum point is reached at an operating voltage near $11.2 \mathrm{~V}$ and full thermal recovery is observed near the thermal neutral voltage of $12.9 \mathrm{~V}$. The magnitude of the stack cooling and heating effects is greatest at the center of the stack, as indicated by the response of internal stack temperature 1. Internal stack temperatures 2 and 3 respond similarly to the center thermocouple, but with smaller amplitude, due to convective and radiative heat transfer effects near the edges of the stack. Stack internal \#4 is in the top air flow channel, so its response is also constrained by radiant heat transfer. Note that the "furnace" thermocouple responds in a direction that is opposite of the stack internal thermocouples. This is because the feedback control demands more furnace power when the stack is tending to cool off and less power when the stack is tending to heat up. Figure 8 also shows the mean electrolyte temperature predicted from a FLUENT simulation obtained at the operating conditions of sweep \#4. The trend of the mean electrolyte temperatures with respect to operating voltage is similar to the trend observed with the thermocouple readings. However, the magnitude of the predicted temperature variation is greater than what was measured. This could due to the fact that the FLUENT model, as it was configured for these calculations, does not include internal radiation heat transfer. We plan to investigate this effect further in our future modeling efforts.

Contour plots representing local FLUENT results for electrolyte temperature and current density are presented in Figs. 9 and 10 . In these figures, the steam/hydrogen flow is from top to bottom and the air flow is from left to right. Figure 9 shows electrolyte temperature contour plots for amperages of 10,15, and 30 amps. These current values correspond to

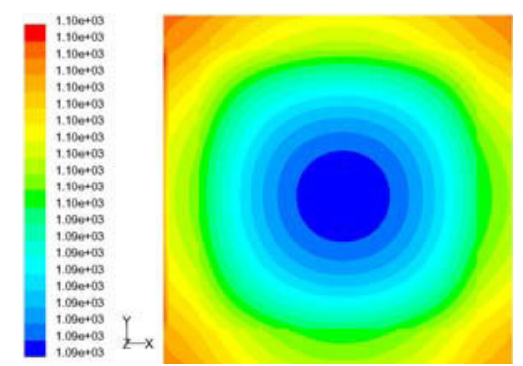

(a)

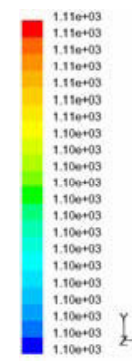

$-x$

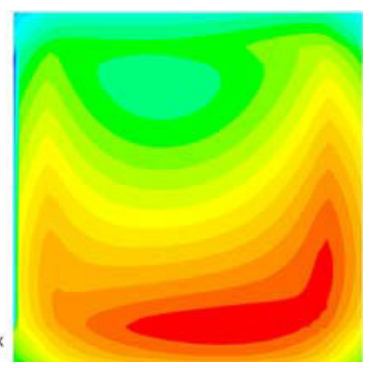

(b)

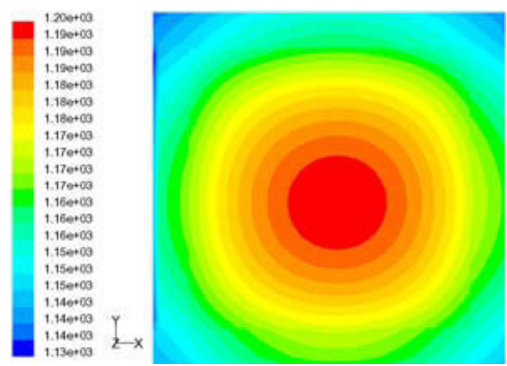

(c)

Figure 9. Temperature $(K)$ contours on the electrolyte and insulator for currents of 10 , 15 , and 30 amps.
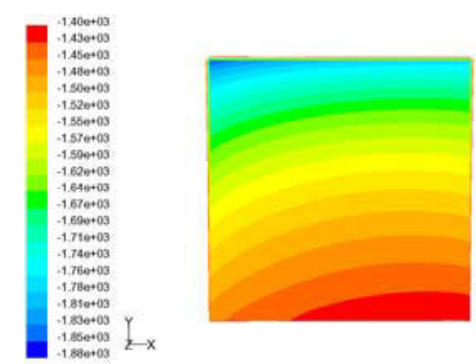

(a)

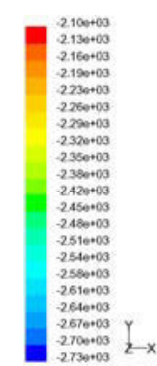

a)

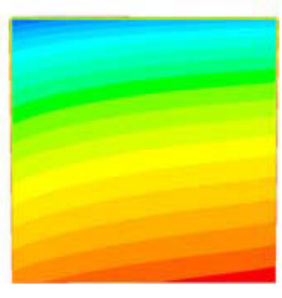

(b)
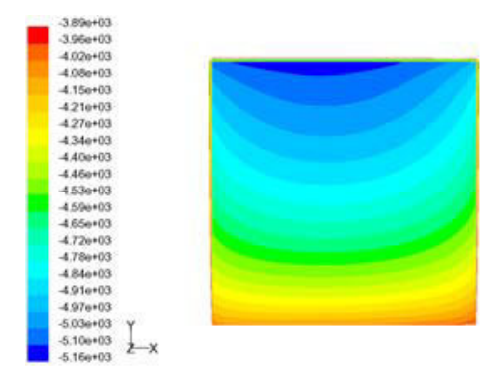

(c)

Figure 10. Current density $\left(\mathrm{A} / \mathrm{m}^{2}\right)$ contours on the electrolyte for currents of 10,15 , and 30 amps. 
operating voltage regions shown on Figure 8 near the minimum electrolyte temperature (10 amps), near thermal neutral voltage (15 amps), and in the region dominated by ohmic heating (30 amps). The radiant boundary condition at $1103 \mathrm{~K}$ tends to hold the outside of the model at a higher temperature for the 10-amp case (Fig. 9 (a)), while the endothermic heat requirement maintains the center of the electrolyte at a lower temperature. Minimum and maximum temperatures for this case are $1091 \mathrm{~K}$ and $1100 \mathrm{~K}$ respectively. The center Fig. 9 (b) shows a temperature difference across the electrolyte of only one degree $\mathrm{K}$, with values very near 1103 $\mathrm{K}$; this current density is very near the thermal neutral voltage. Fig. 9 (c) shows that ohmic heating in the electrolyte is dominating and the thermal boundary condition is keeping the edges cooler than the inside. Minimum and maximum temperatures are $1139 \mathrm{~K}$ and $1197 \mathrm{~K}$, respectively, for this case.

Contour plots of local current density on the electrolyte are shown in Figure 10 for 10, 15 , and 30 amps. Mean current densities for these three cases are: $0.156,0.234$, and 0.469 A/cm2. These plots correlate directly with local hydrogen production rates. Since FLUENT is being run in electrolysis mode, the current density values are all negative and hence the blue values have the largest magnitudes. Highest current density magnitudes occur near the steam hydrogen inlet (the top of the figures). This corresponds to the location of the greatest steam concentration. The orange areas show where the current density is lowest because the available steam concentration is lower.

\section{SUMMARY AND CONCLUSIONS}

A research program is under way at the Idaho National Laboratory to assess the performance of solid-oxide cells operating in the steam electrolysis mode for hydrogen production over a temperature range of 800 to $900^{\circ} \mathrm{C}$. The research program includes both experimental and modeling activities. Selected results from both activities have been presented in this paper. Experimental results were obtained from a ten-cell planar electrolysis stack, with a per-cell active area of $64 \mathrm{~cm}^{2}$, fabricated by Ceramatec, Inc. The electrolysis cells are electrolyte-supported, with scandia-stabilized zirconia electrolytes $(\sim 140 \mu \mathrm{m}$ thick), nickel-cermet steam/hydrogen electrodes, and manganite air-side electrodes. The metallic interconnect plates are fabricated from ferritic stainless steel. The experiments were performed over a range of steam inlet mole fractions $(0.1-0.6)$, gas flow rates $(1000-4000$ sccm), and current densities $\left(0\right.$ to $\left.0.38 \mathrm{~A} / \mathrm{cm}^{2}\right)$. Steam consumption rates associated with electrolysis were measured directly using inlet and outlet dewpoint instrumentation. Cell operating potentials and cell current were varied using a programmable power supply. DC potential sweeps performed on this stack demonstrated the effects of steam flow rate on stack performance. High ASR values and steam starvation were observed for the low-steam-content sweeps. A per-cell ASR value of 2.2 was demonstrated for a high-steam-content DC potential sweep at $830^{\circ} \mathrm{C}$. Hydrogen production rates measured by the change in dewpoint of the gas flows were shown to be in excellent agreement with hydrogen production rates based on stack current. Hydrogen production rates up to 90 Normal liters per hour were demonstrated. Internal stack temperatures measured with miniature thermocouples A stack cooling effect was directly observed for stack operating voltages between the open-cell potential and the thermal neutral voltage.

A three-dimensional computational fluid dynamics (CFD) model was also created to model high-temperature steam electrolysis in a planar solid oxide electrolysis cell (SOEC). The model represents a single cell as it would exist in the experimental electrolysis stack. 
Mass, momentum, energy, and species conservation and transport are provided via the core features of the commercial CFD code FLUENT. A solid-oxide fuel cell (SOFC) model adds the electrochemical reactions and loss mechanisms and computation of the electric field throughout the cell. The FLUENT SOFC user-defined subroutine was modified for this work to allow for operation in the SOEC mode. Model results provide detailed profiles of temperature, Nernst potential, operating potential, anode-side gas composition, cathode-side gas composition, current density and hydrogen production over a range of stack operating conditions. Mean model results were shown to compare favorably with the experimental results obtained from the ten-cell stack tested at INL. At operating voltages between the opencell potential and thermal neutral, electrolyte temperatures are below $1103 \mathrm{~K}$. A thermal minimum temperature occurs near $1.08 \mathrm{~V}$. For operating voltages above thermal neutral, ohmic heating dominates and resultant electrolyte temperatures rapidly increase beyond 1103 $\mathrm{K}$. Contour plots of local electrolyte temperature and current density indicated the effects of heat transfer, reaction cooling/heating, and change in local gas composition.

\section{ACKNOWLEDGEMENTS}

This work was supported by the US Department of Energy, Office of Nuclear Energy, Nuclear Hydrogen Initiative Program.

\section{REFERENCES}

FLUENT Theory Manual, version 6.1.22, Fluent Inc., Lebanon, New Hampshire, 2004.

Herring, J. S., O'Brien, J. E., Stoots, C. M., Lessing, P. A., Anderson, R. P., Hartvigsen, J. J., and Elangovan, S., "Hydrogen Production from Nuclear Energy via High-Temperature Electrolysis," presented at the 2004 International Conference on Advances in Nuclear Power Plants (ICAPP '04), June 13-17, 2004, Pittsburgh, PA.

Herring, J. S., O'Brien, J. E., Stoots, C. M., Lessing, P. A., Anderson, R. P., Hartvigsen, J. J., and Elangovan, S., "Hydrogen Production through High-Temperature Electrolysis Using Nuclear Power," presented at the AIChE Spring National Meeting, New Orleans, April 25 29, 2004.

International Atomic Energy Agency (IAEA), May 1999, Hydrogen as an energy carrier and its production by nuclear power, IAEA-TECDOC-1085.

National Academy of Sciences, National Research Council, The Hydrogen Economy: Opportunities, Costs, Barriers, and R\&D Needs, February, 2004.

O'Brien, J. E., Stoots, C. M., Herring, J. S., and Lessing, P. A., "Characterization of SolidOxide Electrolysis Cells for Hydrogen Production via High-Temperature Steam Electrolysis," Proceedings, $2^{\text {nd }}$ International Conference on Fuel Cell Science, Engineering, and Technology, June 14-16, 2004, Rochester, NY, paper\# 2474, pp., 219 228.

O'Brien, J. E., Stoots, C. M., Herring, J. S., and Lessing, P. A., "Performance Measurements of Solid-Oxide Electrolysis Cells for Hydrogen Production from Nuclear Energy," Proceedings, $12^{\text {th }}$ ICONE Meeting, April 25-29, 2004, Arlington, VA, paper \# ICONE1249479.

Prinkey, M., Shahnam, M., and Rogers, W. A., "SOFC FLUENT Model Theory Guide and User Manual," Release Version 1.0, FLUENT, Inc., 2004.

Yildiz, B., and Kazimi, M. S., "Nuclear Energy Options for Hydrogen and Hydrogen-Based Liquid Fuels Production," MIT-NES-TR-001, September 2003. 